\title{
Effects of same-category and different-category extraneous memory sets on item recognition
}

\author{
DON DIENER \\ University of Nevada, Las Vegas, Nevada
}

\begin{abstract}
In a study designed to distinguish between parallel and serial models of performance on Sternberg's item recognition task, Krueger (1975) presented subjects with a memory set (the "added" set) followed by a second ("core") set, a probe to the core set, and finally a probe to the added set. Response latency (RT) to both the core- and added-set probes initially increased with the size of the extraneous set. Over successive blocks of trials, the effect of the size of the extraneous set diminished. In Experiment 1 of the present study, Krueger's basic procedures were replicated with results similar to those he reported for early trials. Experiment 2 was a variation on the added-set procedure. Rather than the memory sets' being drawn from different categories (letters and digits), both sets consisted of digits. On half of the negative trials for both the core and the added tasks, the probe was drawn from the extraneous set, forcing the subjects to separate the two sets. Although RT on the core task did not increase with the size of the added set, there was an increase in RT to the added set with increases in core-set size, a finding inconsistent with the serial search model.
\end{abstract}

Sternberg $(1966,1969)$ presented subjects with a memory set consisting of a series of one to six different digits. This "positive set" was followed in about $2 \mathrm{sec}$ by a single "probe" digit. The subjects' task was to indicate, by depressing the appropriate lever, whether the probe digit was a member of the positive set. Early findings with this procedure included a linear increase in response latency (RT) with increasing set size, equal slopes of the response latency function for positive ("targets") and negative ("distractors") probes, and the absence of an effect of the serial position of items within the positive set. Sternberg concluded from this pattern of results that the search of the memory set is serial and exhaustive.

A substantial number and variety of models of performance on the item recognition task have been proposed since the publication of Sternberg's results. Most of these models assume parallel access to members of the memory set or to the representations of all potential members of the memory set. A good deal of research has been devoted to contrasting predictions made on the basis of different models. A number of findings that present difficulties for the serial-exhaustive model have been adduced, including serial position effects (e.g., Aubé \& Murdock, 1974; Corballis, Kirby, \& Miller, 1972), characteristics of individual RT distributions (e.g., Hockley, 1984; Hockley \& Corballis, 1982; Ratcliff \& Murdock, 1976), and greater slopes of positive than of negative RT functions (see Cavanagh, 1976, for a discussion). However, despite 25 years of research and a good deal of published

Thanks to Heidi Nagel and Julie Beasley for their help in collecting the data. Address correspondence to D. Diener, Department of Psychology, University of Nevada, Las Vegas, 4505 Maryland Parkway, Las Vegas, NV 89154. data, there is insufficient evidence to compel a choice among alternative parallel models or even to show conclusively that the serial search model is wrong.

In a study designed to distinguish between serial and parallel models of the memory search, Krueger (1975) presented subjects with two concurrent item recognition tasks. One complete task was interposed between the presentation of the memory set and presentation of the probe for the other task. That is, a positive set was presented, followed by a second positive set, then a probe to this second set, and finally a probe to the first set. The first set presented was designated the "added" set, and the second, the "core" set. The instructions to the subjects did not stress performance on one set over the other. The added set contained $0,1,2$, or 4 items; the core set contained 1,2 , or 4 . For half the subjects, the added set was drawn from the letters $A$ through $\mathrm{H}$, and $\mathrm{K}$, and the core set was drawn from the digits 1 through 9 . For the other half of the subjects, the added set consisted of letters and the core set of digits.

Most parallel models of memory search predict an increase in RT with increases in the size of the extraneous set, either because of increased demands for processing capacity or because of reduced trace strength of individual items. According to the latter trace-strength view, as set size increases, the trace strength of each item in the set decreases. Because decisions about the membership of the probe in the positive set are based on determining whether the trace strength associated with the memory representation of the probe exceeds a criterion level, RT increases with decreasing trace strength of targets and increasing trace strength of distractors.

Maintaining an extraneous set in memory presumably requires the same resources as maintaining the "target" set (the set designated for the search). Therefore, in- 
creases in the size of an extraneous set should lower the trace strength of items in the target set just as increases in the size of the target set. It is possible, however, that, through directed rehearsal, the effect of the size of the extraneous set might be smaller than that of target set size.

The most straightforward version of the serial search model predicts that the size of the extraneous set would have little effect on RT. Subjects simply limit their search to the target set, ignoring the extraneous set. It is possible, however, that subjects search a larger set consisting of the union of the core and added sets. In this case, RT would increase equally with increases in the size of either set. Thus, finding no increase in RT with the size of the extraneous set would support the serial position model, but finding an effect similar to that of target set size would be inconclusive.

Krueger found that RT to the target set increased with both the size of the target and the extraneous set. The effect of the size of the extraneous set, however, diminished over successive blocks of trials. It was not possible to determine whether this change in performance with practice was due to the subjects' learning to direct a (serial) search to only one of the sets or to their ability to alter the relative trace strength of the two sets by means of directed rehearsal. Although the major finding of the study was inconclusive from a theoretical perspective, higher error rates and shorter RTs for positive than for negative responses seemed to reflect differences in the effective trace strength of items. Krueger argued, therefore, that his results were most compatible with a parallel, trace strength model of memory search.

\section{EXPERIMENT 1}

In the present Experiment 2, Krueger's (1975) addedset procedure was employed with two sets of digits in a procedure designed to force the subjects to maintain a separation between the two sets. Experiment 1 was a replication of Krueger's study under conditions intended to facilitate comparison with the results of Experiment 2. Differences between the present procedure and that of Krueger include a faster presentation rate for items in the positive set $(1 \mathrm{sec} /$ item vs. $1.6 \mathrm{sec} / \mathrm{item})$ and the use of slightly different set sizes.

\section{Method}

\section{Subjects}

Eleven men and 17 women, recruited from a number of psychology classes in exchange for "bonus points," participated in the study. The subjects ranged in age from 18 to 43 years with a median age of 20 years.

\footnotetext{
Apparatus

An APPLE IIgs microcomputer was used to present stimuli, record responses, and measure RTs. The stimuli were presented on the Apple color monitor in the 40-column display mode. In this display, numerals are formed on $5 \times 7$ pixel grids (approximately $4 \times 6 \mathrm{~mm}$; a visual angle of about $230^{\circ}$ at a $45-\mathrm{cm}$ viewing dis-
}

Table 1

Mean Latencies and Standard Errors for Positive and Negative Responses for Each Combination of Sizes of the Letter and Digit Sets in Experiment 1

\begin{tabular}{|c|c|c|c|c|c|c|c|}
\hline \multirow[b]{4}{*}{ Trials } & \multicolumn{5}{|c|}{ Set Size } & & \\
\hline & \multirow[b]{3}{*}{ Digits } & \multicolumn{6}{|c|}{ Letters } \\
\hline & & \multicolumn{2}{|c|}{1} & \multicolumn{2}{|c|}{2} & \multicolumn{2}{|c|}{3} \\
\hline & & $M$ & $S E$ & $M$ & $S \underline{S E}$ & $M$ & $S E$ \\
\hline \multicolumn{8}{|c|}{ Letter Set Latencies } \\
\hline \multirow[t]{3}{*}{ Positive } & 1 & 654 & 22 & 727 & 21 & 779 & 25 \\
\hline & 2 & 679 & 22 & 732 & 24 & 781 & 25 \\
\hline & 3 & 678 & 21 & 806 & 25 & 815 & 28 \\
\hline \multirow[t]{3}{*}{ Negative } & 1 & 760 & 25 & 811 & 21 & 814 & 22 \\
\hline & 2 & 778 & 26 & 810 & 21 & 841 & 23 \\
\hline & 3 & 809 & 27 & 820 & 25 & 857 & 25 \\
\hline \multicolumn{8}{|c|}{ Digit Set Latencies } \\
\hline \multirow[t]{3}{*}{ Positive } & 1 & 554 & 23 & 633 & 21 & 639 & 22 \\
\hline & 2 & 662 & 22 & 688 & 27 & 700 & 27 \\
\hline & 3 & 660 & 17 & 710 & 25 & 699 & 22 \\
\hline \multirow[t]{3}{*}{ Negative } & 1 & 652 & 21 & 712 & 23 & 707 & 23 \\
\hline & 2 & 670 & 19 & 731 & 25 & 753 & 25 \\
\hline & 3 & 736 & 22 & 754 & 22 & 807 & 26 \\
\hline
\end{tabular}

tance). The subjects observed the display from the distance that they found most comfortable.

\section{Procedure}

Each trial consisted of the following sequence of events: A memory set consisting of one to three different digits drawn randomly from the set 0-9 was presented sequentially in the center of the screen at the rate of one digit/second. After the last digit in this set had been displayed, the area where the digits had been displayed was covered by a white square for a $2-\sec$ delay interval. Immediately following the delay, a second memory set, consisting of one to three letters drawn randomly from the set $\mathrm{A}-\mathrm{J}$ was presented sequentially at the same location and rate as the first. The

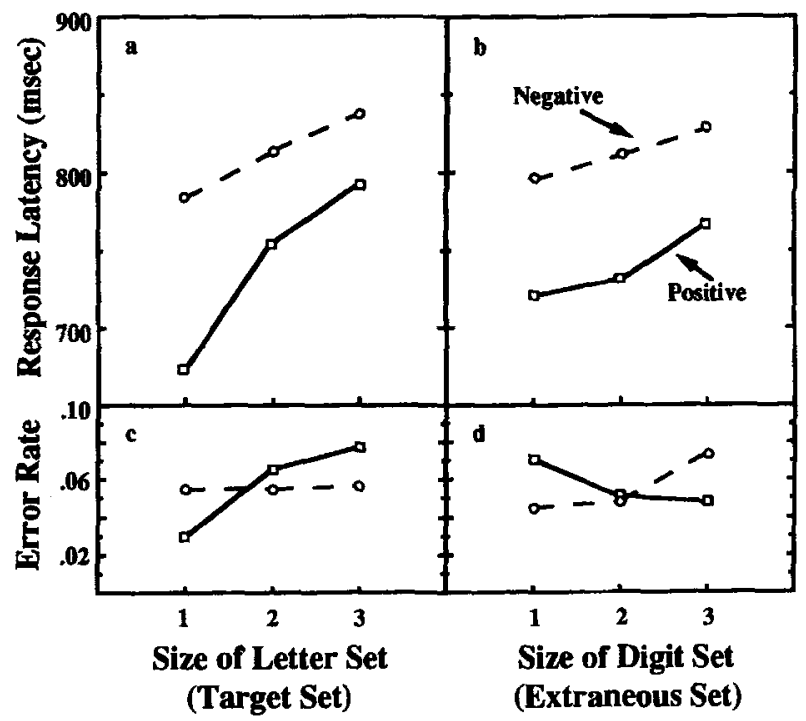

Figure 1. Mean response latency and error rates for positive and negative responses on the letter task of Experiment 1, as a function of the size of the target and extraneous sets. 
Table 2

Analysis of Variance Table for Response Latency and Error Rates from the Letter Set of Experiment 1

\begin{tabular}{|c|c|c|c|c|c|c|c|}
\hline \multirow[b]{3}{*}{ Source } & \multirow[b]{3}{*}{$d f$} & \multicolumn{3}{|c|}{ Response Latency } & \multicolumn{3}{|c|}{ Error Rate } \\
\hline & & \multicolumn{2}{|c|}{ Mean Squares } & \multirow[b]{2}{*}{$F$} & \multicolumn{2}{|c|}{ Mean Squares } & \multirow[b]{2}{*}{$F$} \\
\hline & & Effect & Subject $\times$ Effect & & Effect & Subject $\times$ Effect & \\
\hline Subject & 27 & $2,170,032$ & & & & .507 & \\
\hline Digit set size & 2,54 & 562,336 & 71,138 & $7.90 \dagger$ & .019 & .007 & 2.71 \\
\hline Letter set size & 2,54 & $2,695,836$ & 62,304 & $43.27 \dagger$ & .007 & .005 & 1.40 \\
\hline Letter probe type & 1,27 & $5,214,965$ & 192626 & $27.07 \dagger$ & .001 & .004 & $<1$ \\
\hline Digit set size $\times$ letter set size & 4,108 & 21,633 & 74,064 & $<1$ & .011 & .005 & 2,20 \\
\hline Digit set size $\times$ letter probe type & 2,54 & 27,215 & 55,258 & $<1$ & .002 & .004 & $<1$ \\
\hline Letter set size $\times$ letter probe type & 2,54 & 425,580 & 60,383 & $7.05^{*}$ & .009 & .007 & 1.29 \\
\hline \multicolumn{8}{|l|}{ Digit set size $\times$ letter set size } \\
\hline$\times$ letter probe type & 4,108 & 94,570 & 63,428 & 1.49 & .004 & .004 & $<1$ \\
\hline
\end{tabular}

last letter in this set was again followed by a 2 -sec display of the white square. This square was replaced by a test letter. Subjects responded to the test letter by pressing the " $\mathrm{K}$ " key on the computer keyboard with the right index finger to indicate that the letter was a member of the second memory set or by pressing the " $D$ " key with the left index finger to indicate that it was not. One second following the subject's response, a test digit to the first memory set was presented. The subjects responded to this test digit in the same way as to the first.

If the subject's response to either of the test stimuli was incorrect, occurred before the test stimulus had been displayed for $100 \mathrm{msec}$, or occurred after the test stimulus had been displayed for $1,500 \mathrm{msec}$, the subject was so informed by an appropriate message briefly displayed on the screen. In the case of any of these errors, the RT data were excluded from analysis and the trial was replaced by another with the same characteristics. Unless an error occurred on one of the last three trials, when replacement was immediate, trials were replaced three trials subsequent to the trial on which the error was made. If both responses were correct and occurred within the appropriate time window, the subject was instructed by a message on the screen to press the space bar to begin a new trial.

The 128 trials on the task consisted of 4 trials for each combination of digit set size, test digit type, letter set size, and test letter type. On positive trials, the serial position of the target stimulus in the series was determined randomly. On any trial, all serial positions and sets of distractor stimuli were equally probable.

A message on the computer screen informed the subjects when half the trials had been completed and instructed them to take a short break if they so desired. The entire procedure took about $45 \mathrm{~min}$.

\section{Results}

Mean RTs and standard errors for each combination of sizes of the letter and digit sets on both the letter and digit tasks are shown in Table 1.

\section{Letter (Core) Set}

RT and error rates for the letter set are shown as a function of both letter set size and digit set size in Figure 1.

Response latency. A within-subjects (digit set size $\times$ letter set size $\times$ letter probe type $\times$ subject) analysis of variance (ANOVA) was performed on the RT data. The results of this ANOVA are shown in Table 2. The increases in RT with the size of the digit (added) set and the size of the letter set apparent in Figure 1 were significant, as was the effect of probe type. The probe type $\times$ letter set size interaction was significant because of a steeper slope of the RT function for positive than for negative responses. No other interactions approached significance.

Statistics describing the regressions of positive, negative, and mean response latency on set size are shown in Table 3 . The $95 \%$ confidence intervals shown in the table are based on a subject $X$ set size trend analysis. The effect of the size of the extraneous digit set was roughly half the effect of the target letter set.

The effect of the serial position of the target on positive trials was analyzed in separate ANOVAs for set sizes of two and three letters. No significant serial position effects were found. However, because of the potential relevance of serial position effects to theoretical interpretation, a breakdown of positive responses by target set size and serial position is presented as an Appendix.

Errors. The overall error rate for the letter set was .089. An ANOVA similar to that performed on the RT

Table 3

Slopes and Intercepts, With $95 \%$ Confidence Intervals, and Correlations Describing the Regressions of Positive, Negative, and Mean Response Latencies on Letter Set and Digit Set Size for Both Tasks in Experiment 1

\begin{tabular}{|c|c|c|c|c|}
\hline \multirow{2}{*}{$\begin{array}{c}\text { Set } \\
\text { Size }\end{array}$} & \multirow{2}{*}{$\begin{array}{c}\text { Probe } \\
\text { Type }\end{array}$} & \multicolumn{2}{|c|}{ Response Latencies } & \multirow[b]{2}{*}{$r$} \\
\hline & & Slope & Intercept & \\
\hline \multicolumn{5}{|c|}{ Letter Sets } \\
\hline Letter & $\begin{array}{l}\text { positive } \\
\text { negative } \\
\text { mean }\end{array}$ & $\begin{array}{l}60.88 \pm 13.00 \\
27.27 \pm 14.05 \\
44.06 \pm 9.67\end{array}$ & $\begin{array}{l}617.4 \pm 18.4 \\
756.6 \pm 19.9 \\
687.0 \pm 13.6\end{array}$ & $\begin{array}{l}.975 \\
.997 \\
.984\end{array}$ \\
\hline Digit & $\begin{array}{l}\text { positive } \\
\text { negative } \\
\text { mean }\end{array}$ & $\begin{array}{l}23.35 \pm 13.73 \\
16.64 \pm 13.77 \\
20.00 \pm 10.31\end{array}$ & $\begin{array}{l}692.5 \pm 19.4 \\
777.8 \pm 19.5 \\
735.1 \pm 14.6\end{array}$ & $\begin{array}{l}.954 \\
.997 \\
.999\end{array}$ \\
\hline \multicolumn{5}{|c|}{ Digit Sets } \\
\hline Letter & $\begin{array}{l}\text { positive } \\
\text { negative } \\
\text { mean }\end{array}$ & $\begin{array}{l}26.86 \pm 13.64 \\
34.78 \pm 13.64 \\
30.82 \pm 8.84\end{array}$ & $\begin{array}{l}607.1 \pm 19.3 \\
655.1 \pm 19.3 \\
631.1 \pm 12.5\end{array}$ & $\begin{array}{l}.882 \\
.982 \\
.946\end{array}$ \\
\hline Digit & $\begin{array}{l}\text { positive } \\
\text { negative } \\
\text { mean }\end{array}$ & $\begin{array}{r}40.37 \pm 15.43 \\
37.72 \pm 14.34 \\
39.05 \pm 9.91\end{array}$ & $\begin{array}{l}580.1 \pm 21.8 \\
649.3 \pm 10.1 \\
614.6 \pm 14.0\end{array}$ & $\begin{array}{l}.898 \\
.989 \\
.984\end{array}$ \\
\hline
\end{tabular}


measure was performed on the error rates. No significant main effects or interactions were found (see Table 2). Separate ANOVAs revealed that the serial position of the target on positive trials did not significantly affect the error rates.

\section{Digit (Added) Set}

Response latency and error rates for the digit set are shown as a function of both letter and digit set size in Figure 2.

Response latency. Digit set response latency data were analyzed in a manner similar to that employed for the comparable data for the letter set, except that, because the response to the digit set came after the response to the letter set, the effects of both probe types were assessed. The ANOVA table is presented as Table 4. Only the effects of digit set size, digit probe type, letter set size, and letter probe type were significant. Separate ANOVAs for each set size revealed no significant serial position effects (see the Appendix for a serial position breakdown). As shown in Table 3, the slopes of the functions relating RT to the size of the extraneous letter set were fairly large, averaging over three fourths the size of the slopes of the functions for the target set.

Errors. The overall error rate for the digit set was .058. An ANOVA performed on the error rates (see Table 4) revealed no significant effect of digit set size. The effect of the letter set size, however, was significant. The main effect of digit probe type was significant, with a higher error rate on positive (.076) than on negative $(.040)$ trials. There was a significant interaction between digit set size and digit probe type. Errors on negative trials tended to decrease with set size, whereas errors on

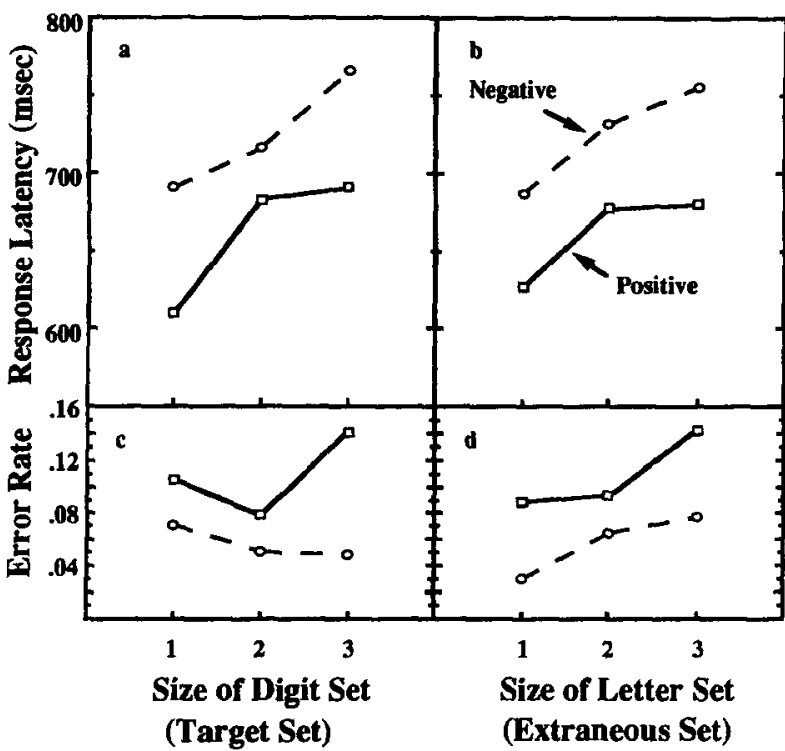

Figure 2. Mean response latency and error rates for positive and negative responses on the digit task of Experiment 1, as a function of the size of the target and extraneous sets.

positive trials increased slightly. Separate ANOVAs revealed no significant serial position effects on error rates.

\section{Discussion}

The results of the present Experiment 1 are similar to those reported by Krueger (1975). The mean RTs from the two studies are similar, although the present error

Table 4

Analysis of Variance Table for Response Latency and Error Rates from the Digit Set of Experiment 1

\begin{tabular}{|c|c|c|c|c|c|c|c|}
\hline \multirow[b]{3}{*}{ Source } & \multirow[b]{3}{*}{$d f$} & \multicolumn{3}{|c|}{ Response Latency } & \multicolumn{3}{|c|}{ Error Rate } \\
\hline & & \multicolumn{2}{|c|}{ Mean Squares } & \multirow[b]{2}{*}{$r$} & \multicolumn{2}{|c|}{ Mean Squares } & \multirow[b]{2}{*}{$F$} \\
\hline & & Effect & Subject $\times$ Effect & & Effect & Subject $\times$ Effect & \\
\hline Subject & 27 & & $2,030,553$ & & & .089 & \\
\hline Digit set size & 2,54 & $2,116,254$ & 65,681 & $32.22 \ddagger$ & .038 & .020 & 1.90 \\
\hline Digit probe type & 1,27 & $4,114,061$ & 99,404 & $41.39 \ddagger$ & .340 & .036 & $9.44 \dagger$ \\
\hline Letter set size & 2,54 & $1,426,521$ & 52,215 & $27.32 \ddagger$ & .109 & .017 & $6.41 \dagger$ \\
\hline Letter probe type & 1,27 & $1,845,348$ & 70,215 & $26.28 \ddagger$ & .002 & .011 & $<1$ \\
\hline Digit set size $\times$ digit probe type & 2,54 & 220,557 & 82,682 & 2.67 & .055 & .017 & $3.24^{*}$ \\
\hline Digit set size $\times$ letter set size & 4,108 & 37,422 & 52,277 & $<1$ & .006 & .015 & $<1$ \\
\hline Digit set size $\times$ letter probe type & 2,54 & 158,559 & 67,947 & 2.33 & .001 & .014 & $<1$ \\
\hline Digit probe type $\times$ letter set size & 2,54 & 40,188 & 72,116 & $<1$ & .020 & .025 & $<1$ \\
\hline Digit probe type $\times$ letter probe type & 1,27 & 233,783 & 96,072 & 2.43 & .001 & .025 & $<1$ \\
\hline Letter set size $\times$ letter probe type & 2,54 & 100,484 & 67,559 & 1.49 & .013 & .014 & $<1$ \\
\hline \multicolumn{8}{|l|}{ Digit set size $\times$ digit probe type } \\
\hline$\times$ letter set size & 4,108 & 83,397 & 65,259 & $<1$ & .012 & .018 & $<1$ \\
\hline \multicolumn{8}{|l|}{ Digit set size $\times$ digit probe type } \\
\hline$\times$ letter probe type & 2,54 & 9,910 & 49,621 & $<1$ & .017 & .016 & 1.06 \\
\hline \multicolumn{8}{|l|}{ Digit probe type $\times$ letter probe type } \\
\hline$\times$ letter set size & 2,54 & 34,540 & 47,857 & $<1$ & .005 & .015 & $<1$ \\
\hline \multicolumn{8}{|l|}{ Digit set size $\times$ letter set size } \\
\hline$\times$ letter probe type & 4,108 & 30,223 & 56,486 & $<1$ & .012 & .019 & $<1$ \\
\hline $\begin{array}{l}\text { Digit set size } \times \text { digit probe type } \times \\
\text { letter set size } \times \text { letter probe type }\end{array}$ & 4,108 & 50,136 & 52,737 & $<1$ & .001 & .019 & $<1$ \\
\hline
\end{tabular}


rates are somewhat higher. In both studies, the size of the target sets and the size of the extraneous sets affected RT, with the effect of target set size being somewhat greater than that of the extraneous set size.

Krueger's subjects participated in four blocks of 60 trials, compared to 128 total trials in the present study. The effect of the size of the extraneous set diminished over successive blocks of trials. A comparison of the slopes of the RT functions from the present study and those from both the first 120 and the last 60 trials of Krueger's study is presented in Table 5. The slopes from the present study are similar to those reported by Krueger for the first 120 trials, except that the effect of the size of the extraneous set was somewhat smaller in the case of the core set and larger in the case of the added set.

Krueger argued that his subjects initially fused the two sets into a single larger set consisting of digits and letters, thus accounting for the effect of the extraneous set on RT. With increasing trials on the task, the subjects were increasingly able to separate the sets accounting for the decrease in the effect of the extraneous set over trials. Experiment 2 of the present study was designed to force the subjects to maintain the two sets separately from the outset. If Krueger's analysis was correct, one would expect little effect of extraneous set size.

\section{EXPERIMENT 2}

In Experiment 2, subjects responded to two different memory sets, both consisting of digits. As in Experiment 1, a complete item-recognition task was interposed between the presentation of the memory set and presentation of the probe for the other task. The size of both memory sets varied from one to three digits. No digit appeared in both sets. On half of the negative trials, for both the core- and the added-set tasks, the probe was a member of the extraneous set, whereas on the other half of the negative trials, the probe was not a member of either set.

The use of different memory sets with members drawn from the same category makes it possible to assess the effect of the membership of the probe in the extraneous set. Consider the case in which a subject is

Table 5

A Comparison of the Slopes (Milliseconds/Item) of Regressions of Response Latencies on Set Size from the Present Study With Those for the First 120 and Last 60 Trials of Krueger (1975)

\begin{tabular}{lccc}
\hline & $\begin{array}{c}c \\
\text { Present } \\
\text { Set }\end{array}$ & \multicolumn{2}{c}{$\begin{array}{c}\text { Trials from } \\
\text { Erueger (1975) }\end{array}$} \\
\cline { 3 - 4 } Experiment 1 & & $1-120$ & $181-240$ \\
$\quad$ Target & 44 & 46 & 43 \\
$\quad$ Extraneous & 20 & 26 & -2 \\
Added & 39 & 41 & 40 \\
$\quad$ Target & 31 & 25 & -5 \\
Extraneous & & & \\
\hline
\end{tabular}

Note-Slopes for Krueger's study were computed from the published data for set sizes of 1,2 , and 4
Table 6

Mean Response Latencies and Standard Errors for Each Probe Type and Combination of Sizes of the Core and Added Sets in Experiment 2

\begin{tabular}{|c|c|c|c|c|c|c|c|}
\hline \multirow[b]{4}{*}{ Trials } & \multicolumn{7}{|c|}{ Set Size } \\
\hline & \multirow[b]{3}{*}{ Added } & \multicolumn{6}{|c|}{ Core } \\
\hline & & \multicolumn{2}{|c|}{1} & \multicolumn{2}{|c|}{2} & \multicolumn{2}{|c|}{3} \\
\hline & & $M$ & $S E$ & $M$ & $S E$ & $M$ & $S E$ \\
\hline \multicolumn{8}{|c|}{ Core-Set Latencies } \\
\hline \multirow[t]{3}{*}{ positive } & 1 & 739 & 32 & 728 & 27 & 809 & 31 \\
\hline & 2 & 672 & 25 & 784 & 26 & 767 & 26 \\
\hline & 3 & 747 & 33 & 731 & 26 & 795 & 32 \\
\hline \multirow[t]{3}{*}{ no-neither } & 1 & 704 & 23 & 770 & 29 & 789 & 28 \\
\hline & 2 & 731 & 28 & 777 & 29 & 803 & 30 \\
\hline & 3 & 687 & 25 & 756 & 29 & 773 & 29 \\
\hline \multirow[t]{3}{*}{ no-added } & 1 & 801 & 29 & 820 & 29 & 849 & 28 \\
\hline & 2 & 749 & 28 & 815 & 32 & 872 & 33 \\
\hline & 3 & 778 & 28 & 810 & 34 & 879 & 31 \\
\hline \multicolumn{8}{|c|}{ Added-Set Latencies } \\
\hline \multirow[t]{3}{*}{ positive } & 1 & 660 & 27 & 663 & 30 & 702 & 28 \\
\hline & 2 & 712 & 30 & 741 & 25 & 720 & 30 \\
\hline & 3 & 763 & 27 & 791 & 27 & 768 & 28 \\
\hline \multirow[t]{3}{*}{ no-neither } & 1 & 706 & 26 & 713 & 26 & 750 & 31 \\
\hline & 2 & 736 & 23 & 741 & 25 & 744 & 29 \\
\hline & 3 & 760 & 28 & 758 & 24 & 820 & 29 \\
\hline \multirow[t]{3}{*}{ no-core } & 1 & 783 & 27 & 779 & 32 & 824 & 33 \\
\hline & 2 & 788 & 25 & 836 & 30 & 835 & 31 \\
\hline & 3 & 846 & 27 & 866 & 31 & 906 & 34 \\
\hline
\end{tabular}

presented with the memory set " $5-3-8$," followed by another set, "7-4-9." The subject is then presented with a probe to the core (i.e., second) set " 5 ." Because this probe is not a member of the core set, the correct response is negative. In addition to allowing an assessment of the effects of membership of the probe in the extraneous set, this procedure forces subjects to separate the two memory sets. Were subjects to fuse the sets into a single larger set, it would be impossible to perform the task.

\section{Method}

\section{Subjects}

Four men and 20 women, recruited from a number of psychology classes in exchange for "bonus points," participated in the study. The subjects ranged in age from 17 to 36 years, with a median age of 20 years.

\section{Procedure}

The apparatus used and procedures followed in Experiment 2 were similar to those of Experiment 1, with the following exceptions. The two memory sets presented to the subjects both consisted of one to three digits. For both the core and the added set, one third of the trials were positive; on one third, a probe was presented that had not occurred in either set (no-neither); and on one third, a probe was presented that was a member of the extraneous set (no-core, or no-added). The subjects were instructed to give the affirmative response only if the probe was a member of the appropriate set. The experiment comprised 81 trials, a single trial for each combination of set size and probe type for the core and added sets.

\section{Results}

Mean RTs and standard errors for each combination of sizes of the core and added sets are shown in Table 6 . 


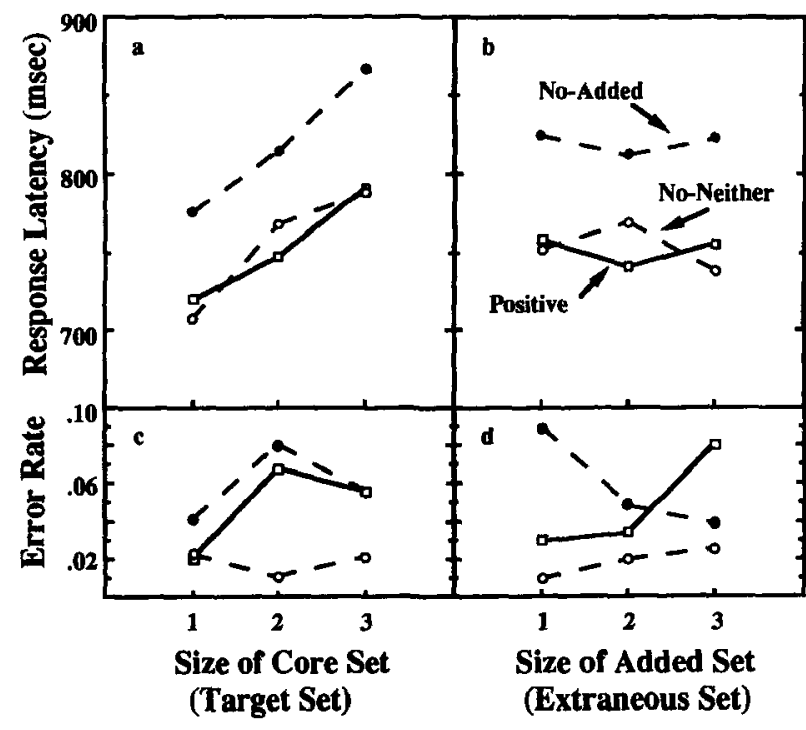

Figure 3. Mean response latency and error rates for positive, no-neither, and no-added responses on the core task of Experiment 2 , as a function of the size of the target and extraneous sets.

\section{Core Set}

RT and error rates for the core set are shown as a function of the size of both the core and added sets in Figure 3. There was no increase in RT with increasing size of the added set for any type of probe. Both RT and error rates were higher for no-added than for no-neither probes.

Response latency. An ANOVA performed on the RT data (see Table 7) confirmed the trends apparent in Figure 3. The effect of the size of the core set was significant, as was the effect of core probe type. The size of the added set had no significant effect. No other main effects or interactions approached significance. Separate ANOVAs revealed no significant serial position effects (see the Appendix for a serial position breakdown).

The slopes of the regressions of core RT on core-set size (see Table 8) were nearly as large as the comparable values from Experiment 1 . The slopes of the func- tions relating RT to the size of the added set, however, were negative for all probe types. None of these negative relationships approached statistical significance.

Errors. The error rate on the core set averaged .041. An ANOVA (see Table 6) revealed a significant effect of core-set size. A trend analysis revealed only a significant quadratic trend $[t(46)=2.29, p<.05]$. The effect of core-probe type was also significant. The effect of added-set size was not significant, but there was a significant added-probe type $\times$ added-set size interaction, with errors on positive and no-neither trials increasing with the size of the added set, whereas errors on no-added trials decreased.

\section{Added Set}

RT and error rates for the added set are shown as a function of the sizes of both sets in Figure 4.

Response latency. An ANOVA (see Table 9) revealed a significant effect of added-set size and addedprobe type. The effect of core-set size and core-probe type on added-set RT were also significant. Added-set responses following no-added probes to the core set were substantially longer $(810 \mathrm{msec})$ than responses following positive $(739 \mathrm{msec})$ or no-neither $(752 \mathrm{msec})$ probes. That is, if the core-set probe was drawn from the added set, added-set RT increased. There was also a complex interaction between added-probe type and core-probe type. Separate ANOVAs revealed no significant serial-position effects (see the Appendix for a serial position breakdown).

The slopes of the functions relating RT to target set size (see Table 8) were similar in magnitude to the comparable values from Experiment 1 and the core set of Experiment 2 . The effect of the size of the extraneous core set, however, was smaller than the comparable effect for the added (digit) set of Experiment 1, although significantly greater than zero for all but positive responses.

Errors. The overall error rate on the added-set task was .079. An ANOVA performed on the error rates revealed a significant effect of both added-set size and core-set size. A core-set size $\times$ subject trend analysis re-

Table 7

Analysis of Variance Table for Response Latency and Error Rates from the Core Set of Experiment 2

\begin{tabular}{|c|c|c|c|c|c|c|c|}
\hline \multirow[b]{3}{*}{ Source } & \multirow[b]{3}{*}{$d f$} & \multicolumn{3}{|c|}{ Response Latency } & \multicolumn{3}{|c|}{ Error Rate } \\
\hline & & \multicolumn{2}{|c|}{ Mean Squares } & \multirow[b]{2}{*}{$F$} & \multicolumn{2}{|c|}{ Mean Squares } & \multirow[b]{2}{*}{$F$} \\
\hline & & Effect & Subject $\times$ Effect & & Effect & Subject $\times$ Effect & \\
\hline Subject & 23 & & $1,329,606$ & & & .239 & \\
\hline Added-set size & 2,46 & 6,173 & 69,443 & $<1$ & .032 & .017 & 1.88 \\
\hline Core-set size & 2,46 & $1,060,103$ & 49,253 & $21.52 \dagger$ & .107 & .025 & $4.28 *$ \\
\hline Core-probe type & 2,46 & 936,226 & 71,533 & $13.09 \dagger$ & .291 & .033 & $8.82 \dagger$ \\
\hline Added-set size $\times$ core-set size & 4,92 & 43,563 & 49,437 & $<1$ & .020 & .026 & $<1$ \\
\hline Added-set size $\times$ core-probe type & 2,92 & 38,529 & 45,957 & $<1$ & .154 & .017 & $9.06 \dagger$ \\
\hline Core-set size $\times$ core-probe type & 4,92 & 22,324 & 39,958 & $<1$ & .062 & .020 & $3.10^{*}$ \\
\hline \multicolumn{8}{|l|}{ Added-set size $\times$ core-set size } \\
\hline$\times$ core-probe type & 8,184 & 46,211 & 49,015 & $<1$ & .037 & .021 & 1.76 \\
\hline
\end{tabular}


Table 8

Slopes and Intercepts, With $95 \%$ Confidence Intervals, and Correlations Describing the Regressions of Positive, No-Neither, No-Added, No-Core, and Mean Response Latencies on Core-Set and Added-Set Size for Both Tasks in Experiment 2

\begin{tabular}{|c|c|c|c|c|}
\hline \multirow{2}{*}{$\begin{array}{c}\text { Set } \\
\text { Size } \\
\end{array}$} & \multirow{2}{*}{$\begin{array}{c}\text { Probe } \\
\text { Type }\end{array}$} & \multicolumn{2}{|c|}{ Response Latencies } & \multirow[b]{2}{*}{$r$} \\
\hline & & Slope & Intercept & \\
\hline \multicolumn{5}{|c|}{ Core Sets } \\
\hline \multirow[t]{4}{*}{ Core } & positive & $35.57 \pm 21.68$ & $681.4 \pm 30.7$ & .993 \\
\hline & no-neither & $40.37 \pm 19.65$ & $673.8 \pm 27.8$ & .962 \\
\hline & no-added & $45.34 \pm 18.86$ & $728.7 \pm 26.7$ & .997 \\
\hline & mean & $40.43 \pm 12.41$ & $694.6 \pm 17.6$ & .9995 \\
\hline \multirow[t]{5}{*}{ Added } & positive & $-.41 \pm 21.63$ & $753.3 \pm 30.6$ & -.041 \\
\hline & no-neither & $-7.84 \pm 17.17$ & $770.2 \pm 24.3$ & -.497 \\
\hline & no-added & $-.71 \pm 27.40$ & $820.7 \pm 38.7$ & -.116 \\
\hline & mean & $-2.99 \pm 14.73$ & $781.4 \pm 20.8$ & -.968 \\
\hline & & Added Sets & & \\
\hline \multirow[t]{4}{*}{ Core } & positive & $9.17 \pm 19.73$ & $705.8 \pm 27.9$ & .821 \\
\hline & no-neither & $18.61 \pm 12.73$ & $710.3 \pm 18.0$ & .908 \\
\hline & no-core & $24.84 \pm 21.69$ & $779.5 \pm 30.7$ & .997 \\
\hline & mean & $17.54 \pm 10.65$ & $731.9 \pm 15.1$ & .997 \\
\hline \multirow[t]{4}{*}{ Added } & positive & $49.64 \pm 21.13$ & $624.8 \pm 29.9$ & 1.000 \\
\hline & no-neither & $28.25 \pm 21.14$ & $691.1 \pm 40.0$ & .977 \\
\hline & no-core & $38.93 \pm 18.17$ & $751.3 \pm 25.7$ & .979 \\
\hline & mean & $38.94 \pm 12.77$ & $689.1 \pm 18.1$ & .992 \\
\hline
\end{tabular}

vealed a significant linear trend $[t(46)=2.89, p<.01]$ with a slope of $1.5 \% /$ item. There was also an interaction between added-probe type and core-probe type. Two consecutive positive or consecutive negative responses produced somewhat higher error rates than did combinations of positive and negative responses. Separate ANOVAs revealed no significant serial position effects.

\section{Discussion}

The increased RT for distractors that were members of an extraneous set in Experiment 2 is consistent with previously reported increases in RT for distractors that are members of immediately prior sets (e.g., Hockley \& Corballis, 1982; Monsell, 1978). This effect can be easily understood from the perspective of models in which the speed of responding varies directly with the trace strength of targets and inversely with the trace strength of distractors. The effect is, however, difficult to explain from the perspective of the serial search model. If only the target set is searched, no match should be found for distractors that are members of the extraneous set. In the absence of a match, membership of the probe in the extraneous set should have no effect on the serial search or on any subsequent stage of processing.

It does not seem plausible that subjects in Experiment 2 searched both the target and the extraneous set. Such searches would yield matches for probes that are members of the extraneous set, resulting, at minimum, in very high error rates. Thus, the increase in RT to the added set with increases in core-set size (albeit smaller than the comparable effect in Experiment 1) does not seem compatible with the serial search model. If a serial search is limited to the target set, the size of the extraneous set should have no effect.

The failure of RT to the core set to increase with added-set size is surprising in view of the effect of coreset size on RT to the added set. One would have expected the size of the extraneous set to have, if anything, a greater effect on the core task than on the added task. When subjects respond to the core set, the added set must be maintained in memory to enable the appropriate response to the added-set probe that follows. When the response is made to the added set, however, the response to the core set has already been made and there is no need for the core set to be maintained in memory.

As indicated by the difference in RT to no-added and no-neither probes, the added set is active in memory at the time of the response to the core set. The failure of the size of the added set to affect RT to the core set suggests that subjects were able to maintain the strength of the core set despite increases in the size of the added set. It seems possible that this could be accomplished through selective rehearsal. However, it is not at all clear why such selective rehearsal would not have the same effect on the added set as well.

In Experiment 1, the effect of extraneous set size on RT to the core (letter) set was also smaller than the effect of extraneous set size on RT to the added (digit) set. The temporal arrangement of the tasks might be responsible for the differences in the effect of the extraneous set on the core and added sets in both experiments. When the core probe is presented, more time has elapsed since the presentation of the last item in the added set (5-7 sec, depending on core-set size) than has elapsed

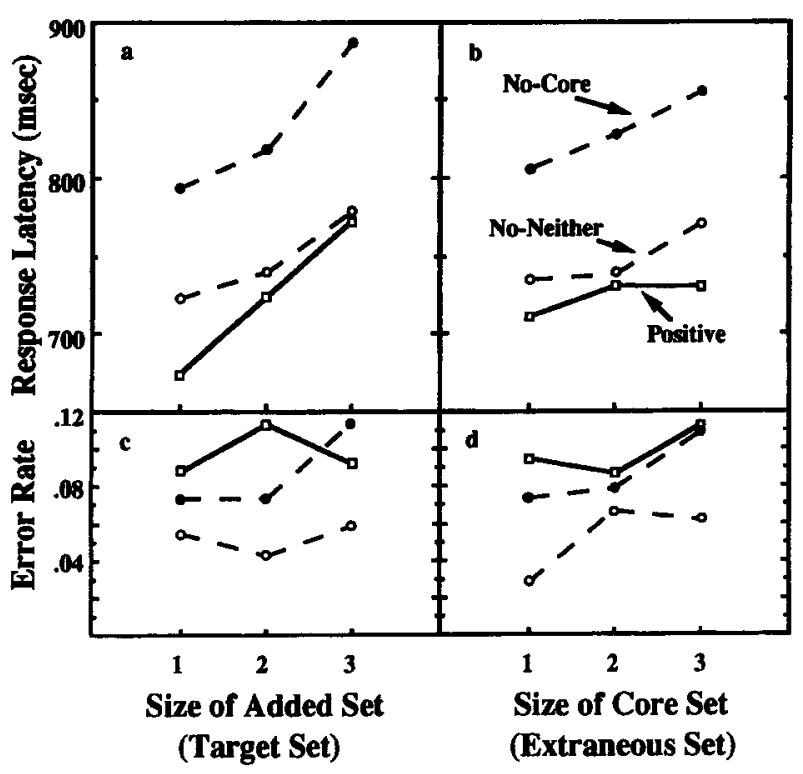

Figure 4. Mean response latency and error rates for positive, no-neither, and no-core responses on the added task of Experiment 2 , as a function of the size of the target and extraneous sets. 
Table 9

Analysis of Variance Table for Response Latency and Error Rates From the Added Set of Experiment 2

\begin{tabular}{|c|c|c|c|c|c|c|c|}
\hline \multirow[b]{3}{*}{ Source } & \multirow[b]{3}{*}{$d f$} & \multicolumn{3}{|c|}{ Response Latency } & \multicolumn{3}{|c|}{ Error Rate } \\
\hline & & \multicolumn{2}{|c|}{ Mean Squares } & \multirow[b]{2}{*}{$F$} & \multicolumn{2}{|c|}{ Mean Squares } & \multirow[b]{2}{*}{$F$} \\
\hline & & Effect & Subject $\times$ Effect & & Effect & Subject $\times$ Effect & \\
\hline Subject & 23 & & $1,363,094$ & & & .262 & \\
\hline Added-set size & 2,46 & 997,577 & 52,133 & $19.14 \ddagger$ & .045 & .032 & 1.41 \\
\hline Added-probe type & 2,46 & $1,971,084$ & 70,601 & $27.92+$ & .363 & .071 & $5.11^{*}$ \\
\hline Core-set size & 2,46 & 200,598 & 36,244 & $5.53 \dagger$ & .138 & .033 & $4.18^{*}$ \\
\hline Core-probe type & 2,46 & 927,649 & 79,512 & $11.67 \ddagger$ & .019 & .042 & $<1$ \\
\hline Added-set size $\times$ added-probe type & 4,92 & 28,515 & 39,161 & $<1$ & .062 & .045 & 1.38 \\
\hline Added-set size $\times$ core-set size & 4,92 & 31,771 & 41,375 & $<1$ & .053 & .047 & 1.13 \\
\hline Added-set size $\times$ core-probe type & 4,92 & 42,420 & 33,933 & 1.25 & .045 & .040 & 1.12 \\
\hline Added-probe type $\times$ core-set size & 4,92 & 25,610 & 36,341 & $<1$ & .038 & .034 & 1.12 \\
\hline Added-probe type $\times$ core-probe type & 4,92 & 227,746 & 39,753 & $5.73+$ & .187 & .024 & $7.79 t$ \\
\hline Core-set size $\times$ core-probe type & 4,92 & 24,041 & 32,839 & $<1$ & .049 & .032 & 1.53 \\
\hline \multicolumn{8}{|l|}{ Added-set size $\times$ added-probe type } \\
\hline \multicolumn{8}{|l|}{ Added-set size $\times$ added-probe type } \\
\hline$\times$ core-set size & 8,184 & 13,914 & 37,878 & $<1$ & .030 & .035 & $<1$ \\
\hline \multicolumn{8}{|l|}{ Added-set size $\times$ core-set size } \\
\hline$\times$ core-probe type & 8,184 & 8,726 & 39,790 & $<1$ & .033 & .036 & $<1$ \\
\hline \multicolumn{8}{|l|}{ Added-probe type $\times$ core-probe type } \\
\hline$\times$ core-set size & 8,184 & 101,857 & 35,091 & $<2.90^{\dagger}$ & .022 & .033 & $<1$ \\
\hline \multicolumn{8}{|l|}{ Added-set size $\times$ added-probe type } \\
\hline$\times$ core-set size $\times$ core-probe type & 16,368 & 42,883 & 40,720 & $<1$ & .021 & .039 & $<1$ \\
\hline
\end{tabular}

from the presentation of the last item in the core set when the added-set probe is presented ( $3 \mathrm{sec}+\mathrm{RT}$ to the core set). It is possible that the procedures employed in Experiment 2 reduced the effect of the extraneous set relative to Experiment 1 for both the core and the added set, and that temporal factors were responsible for the differences between the tasks.

The results of Experiment 2 were considered from a variety of theoretical perspectives, including several serial search and trace-strength models and a hybrid model based on Atkinson and Juola (1974), but these failed to produce a principled quantitative account of the data. Failure to provide a satisfactory theoretical explanation of the data leads naturally to the possibility that the results are unreliable or the result of a seemingly unimportant detail of the procedure.

The results of several unpublished studies attest to the reproducibility of several features of the present pattern of results. A procedure similar to that of the present Experiment 2, using sets of three or four digits for both the core and the added set, produced the same basic findings. There was no significant increase in RT to the core set with an increase in the size of the added set from three to four digits, but RT to the added set increased as much with the size of the extraneous core set as with the size of the target set. In another study similar to Experiment 2, but with a fixed-size (three-digit) core set and an added set that varied from one to four digits, mean RT to the core set actually decreased slightly with increasing size of the added set. Surprisingly, a study using a core set of three letters and an added set of one to four digits showed no significant effect (a 2-msec/item increase) of the size of the added set. Only when the core and added sets consisted of different types of stimuli and both varied in size, as in the present Experiment 1, were effects of added-set size on the core set apparent.

\section{REFERENCES}

Atkinson, R. C., \& Juola, J. F. (1974). Search and decision processes in recognition memory. In D. H. Krantz, R. C. Atkinson, R. D. Luce, \& P. Suppes (Eds.), Contemporary developments in mathematical psychology (Vol. 1, pp. 243-293). San Francisco: W. H. Freeman.

AubÉ, M., \& Murdock, B. (1974). Sensory stores and high-speed scanning. Memory \& Cognition, 2, 27-33.

Cavanagh, P. (1976). Holographic and trace strength models of rehearsal effects in the item recognition task. Memory \& Cognition, 4, 186-199.

Corballis, M. C., Kirby, J., \& Miller, A. (1972). Access to elements of a memorized list. Journal of Experimental Psychology, 94, 185-190.

HoCkLEY, W. E. (1984). Analysis of response time distribution in the study of cognitive processes. Journal of Experimental Psychology: Learning, Memory, \& Cognition, 10, 598-615.

Hockley, W. E., \& Corballis, M. C. (1982). Tests of serial scanning in item recognition. Canadian Journal of Psychology, 36, 189-212.

KrUEGER, L. E. (1975). The effect of an extraneous added memory set on item recognition: A test of parallel-dependent vs. serial-comparison models. Memory \& Cognition, 3, 485-495.

Monsell, S. (1978). Recency, immediate recognition memory and reaction time. Cognitive Psychology, 10, 465-501.

RatClifF, R., \& MURdock, B. B., JR. (1976). Retrieval processes in recognition memory. Psychological Review, 83, 190-214.

SternberG, S. (1966). High-speed scanning in human memory. Science, 153, 652-654

STERnBerG, S. (1969). Memory scanning: Mental processes revealed by reaction-time experiments. American Scientist, 57, 421-457. 
APPENDIX

Mean Response Latencies and Standard Errors of Positive Responses for Each Set Size and Serial Position in Experiments 1 and 2

\begin{tabular}{|c|c|c|c|c|c|c|c|c|c|c|c|c|}
\hline \multirow{4}{*}{$\begin{array}{c}\text { Serial } \\
\text { Position }\end{array}$} & \multicolumn{12}{|c|}{ Set Size } \\
\hline & \multicolumn{6}{|c|}{ Letter Set } & \multicolumn{6}{|c|}{ Digit Set } \\
\hline & \multicolumn{2}{|c|}{1} & \multicolumn{2}{|c|}{2} & \multicolumn{2}{|c|}{3} & \multicolumn{2}{|c|}{1} & \multicolumn{2}{|c|}{2} & \multicolumn{2}{|c|}{3} \\
\hline & RT & $S E$ & $\mathrm{RT}$ & $S E$ & RT & $S E$ & RT & $S E$ & RT & $S E$ & RT & $S E$ \\
\hline \multicolumn{13}{|c|}{ Experiment 1} \\
\hline $\begin{array}{l}1 \\
2 \\
3\end{array}$ & 670 & 12 & $\begin{array}{l}769 \\
744\end{array}$ & $\begin{array}{l}21 \\
18\end{array}$ & $\begin{array}{l}816 \\
784 \\
772\end{array}$ & $\begin{array}{l}28 \\
24 \\
26\end{array}$ & 609 & 14 & $\begin{array}{l}702 \\
668\end{array}$ & $\begin{array}{l}21 \\
17\end{array}$ & $\begin{array}{l}700 \\
676 \\
692\end{array}$ & $\begin{array}{l}23 \\
23 \\
19\end{array}$ \\
\hline \multicolumn{13}{|c|}{ Experiment 2} \\
\hline $\begin{array}{l}1 \\
2 \\
3\end{array}$ & 719 & 17 & $\begin{array}{l}738 \\
758\end{array}$ & $\begin{array}{l}21 \\
23\end{array}$ & $\begin{array}{l}838 \\
771 \\
773\end{array}$ & $\begin{array}{l}33 \\
25 \\
31\end{array}$ & 675 & 16 & $\begin{array}{l}726 \\
722\end{array}$ & $\begin{array}{l}23 \\
23\end{array}$ & $\begin{array}{l}759 \\
796 \\
769\end{array}$ & $\begin{array}{l}30 \\
28 \\
24\end{array}$ \\
\hline
\end{tabular}

(Manuscript received July 23, 1993;

revision accepted for publication November 18, 1993.) 